\title{
Evaluation of selected echinoderms from peninsular Malaysia for cytotoxicity against HepG2 cells, antioxidant and antibacterial activities, and their metabolites profiling
}

\author{
Yosie Andriani ${ }^{1 *}$, Nurul Hazirah Mat Lazim²,3, Asnuzilawati Asari ${ }^{2}$, Faridah Mohamad ${ }^{4}$, Tengku Sifzizul Tengku Muhammad ${ }^{1}$, \\ Noraznawati Ismail ${ }^{1,2}$, Mariam Taib², Hermansyah Amir ${ }^{5}$, Aziz Ahmad², Habsah Mohamad ${ }^{1}$ \\ 'Institute of Marine Biotechnology, Universiti Malaysia Terengganu, Terengganu, Malaysia. \\ ${ }^{2}$ School of Fundamental Science, Universiti Malaysia Terengganu, Terengganu, Malaysia. \\ ${ }^{3}$ Department of Chemistry Malaysia (JKM), Jalan Sultan, Selangor, Malaysia. \\ ${ }^{4}$ School of Marine and Environmental Sciences, Universiti Malaysia Terengganu, Terengganu, Malaysia. \\ ${ }^{5}$ Educational Chemistry Program, Faculty of Teacher Training and Education, Bengkulu University, Bengkulu, Indonesia.
}

\section{ARTICLE INFO \\ Received on: $12 / 06 / 2018$ \\ Accepted on: 19/09/2018 \\ Available online: $31 / 10 / 2018$}

\section{Key words:}

Acanthaster planci,

Echinaster luzonicus,

Echinothrix calamaris, cytotoxicity, antibacterial, antioxidant.

\begin{abstract}
Study on the evaluation of Acanthaster planci, Echinaster luzonicus, and Echinothrix calamaris from Peninsular Malaysia for cytotoxicity against human hepatocellular liver carcinoma cells (HepG2), antioxidant and antibacterial activities were evaluated on their methanol extracts. The cytotoxicity, antioxidant and antibacterial activities were conducted by 3-(4,5-dimethylthiazol-2-yl)-5-(3-carboxymethoxyphenyl)-2-(4sulfophenyl)-2H-tetrazolium assay, 1,1-diphenyl-2-picryl hydrazyl free radical scavenging assay, and disc diffusion method, respectively. In addition, thin layer chromatography (TLC) was done to profile the metabolites within the extracts using Dragendorff's reagent to identify the presence of alkaloids metabolite. The cytotoxicity result showed that the treatment of the extracts (100 $\mathrm{mg} / \mathrm{ml}$ ) inhibited the proliferation of HepG2 cells and the $\mathrm{IC}_{50}$ for all extracts exceeded $30 \mathrm{mg} / \mathrm{ml}$ indicating that the extracts were not cytotoxic to the cells. For antioxidant activity, all extracts showed good antioxidant activity with the $\mathrm{IC}_{50}$ value obtained more than $50 \%$. While, screening of bacterial properties using Gram-positive bacteria strains (Staphylococcus aureus, Bacillus cereus, and Micrococcus sp.) and Gram-negative bacteria strains (Escherichia coli, Salmonella typhimurium, and Pseudomonas aeruginosa) showed that all samples have antibacterial activity against Micrococcus sp. only. The TLC profiling of $A$. planci and E. luzonicus showed the presence of alkaloids. Since the result found that A. planci, E. luzonicus, and E. calamaris have no cytotoxic activity against HepG2 cells (no $\mathrm{IC}_{50}$ value), further study such as anti-atherosclerosis potential agent can be evaluated. Subsequently, a very good antioxidant activity of all samples is also good to screen their potency as an anticancer agent against some cancer cells.
\end{abstract}

\section{INTRODUCTION}

Hepatocellular carcinoma is one of the common malignant primary neoplasma where malignant tumors of the livers can be primary or secondary (Zakaria et al., 2009). In this study, HepG2 cells which used were derived from the liver tissue with unique

"Corresponding Author

Yosie Andriani, Institute of Marine Biotechnology, Universiti Malaysia Terengganu,Terengganu, Malaysia.E-mail: yosieandriani@gmail.com model chromosome numbers of 55 . The cell line was adherent and formed monolayer during cultivation. As an alternative to the current treatment of this disease, many researchers are targeting marine resources due to the fact that marine diversity holds the treasure for natural products that have a significant impact on human healthcare. This study has focused on the organisms from the phylum Echinodermata which are the A. planci, E. luzonicus, and E. calamaris. The A. planci and E. luzonicus belong to the same class, Asteroidea whereas E. calamaris belong to the class Echinoidea (Cleveland et al., 2007). This latter organism has a compact body enclosed in an endoskeleton test or shell and it is 
said to have bioactive compounds in regulating the immune system (Smith et al., 1995). Four classes of echinoderms; Asteroidea, Crinoidea, Holothuroidea, and Ophiuroidea have been reported to exhibit antibacterial and anticancer properties (Bryan et al., 1995; Cheng et al., 2009; Shamsuddin et al., 2010). These organisms are rich with steroid glycosides, gangliosides, thornasterol, sapogenols, and other branched fatty acid including lectins (Dong et al., 2011; Fleming et al., 1974; Ivanchina et al., 2011; Kelly, 2015; Kitagawa et al., 1975). Therefore, based on the potential bioactivity of marine organisms from classes of echinoderms, the aims of this study were to describe the cytotoxicity of the methanol extracts of selected samples (A. planci, E.luzonicus, and E.calamaris) from East coast of Peninsular Malaysia towards the HepG2 cells, to evaluate their antioxidant capacity and antibacterial property towards some selected bacteria ( $S$. aureus, B. cereus, Micrococcus sp, E. coli, $S$. typhimurium, and $P$. aeruginosa). The potential metabolites profiling within the methanol extracts were also identified in this study.

\section{MATERIALS AND METHODS}

\section{Sample preparation and extraction}

The A. planci, E. luzonicus, and E. calamaris were collected from the islands in Terengganu in the East Coast of Peninsular Malaysia via scuba diving in the depth range from 5 to $10 \mathrm{~m}$. The samples were kept in ice prior to reach the laboratory and furthered with processing samples. The A. planci and E. calamaris were separated into two parts which were the outer layer (skin) and visceral organs. The whole E. luzonicus was used and not separated into parts due to the small size. All the samples were then individually freeze-dried and later ground into powder. Furthermore, the powdered samples were extracted three times with methanol followed by solvent evaporation with a rotary evaporator to obtain the crude extract. The weights of the methanolic extracts were recorded.

\section{Reagents}

Minimal essential medium (MEM) was purchased from Santa Cruz (Santa Cruz, CA) and Nacalai (Nacalai Tesque, Kyoto Japan). While Fetal Bovine Serum, 1\% non-essential amino acid, $1 \%$ sodium pyruvate, and $1 \%$ penicillin, streptomycin, and nutrient agar (NA) were purchased from Gibco Diagnostics (Madison, WI). Quercetin, 1,1-diphenyl-2-picryl hydrazyl (DPPH), and others chemicals, solvents, and reagents were of analytical grade and purchased from Sigma Aldrich (Steinheim, Germany).

\section{Cytotoxicity screening assay}

The HepG2 cell was treated with a serial dilution of the methanolic extracts. The extracts were diluted from the highest concentration of $100 \mu \mathrm{g} / \mathrm{ml}$ to the lowest concentration at $0.39 \mu \mathrm{g} /$ $\mathrm{ml}$. Only $5 \mu \mathrm{l}$ of extracts were treated on the cells. The treatments were carried out in eight replicates to ensure the accuracy of the results. The negative control consists of $20 \%$ dimethyl sulfoxide (DMSO) and $80 \%$ of MEM. The positive control was made using vincristine sulfate as it was the standard drug used to treat liver cancer. The cells were incubated for 72 hours in $5 \%$ carbon dioxide incubator at $37^{\circ} \mathrm{C}$. The cytotoxicity of the extracts was determined using 3-(4,5-dimethylthiazol-2-yl)-5-(3-carboxymethoxyphenyl)-
2-(4sulfophenyl)-2H-tetrazolium, where only $20 \mu \mathrm{l}$ of the solution was put in each well and left incubated for one and a half hour in $37^{\circ} \mathrm{C}$ (adopted from Andriani et al., 2015). The viability of the cell was measured using Glomax Multi detection (Promega) at absorbance $490 \mathrm{~nm}$. The graph percentages of inhibition against the $\log _{10}$ concentration of crude extracts were plotted using GraphPad Prism 4.0 software. The value of $\mathrm{IC}_{50}$, the effective concentration of drug that is required for $50 \%$ inhibition, was determined with non-linear regression. The bar chart of the viability of cells against crude concentration was presented in results.

\section{Antioxidant activity}

Antioxidant activity was analyzed using DPPH free radical scavenging assay (Andriani et al., 2017) using the Quercetin as a positive control and DMSO as a negative control. Samples stock were diluted in DMSO and were prepared in varying concentration by two-fold serial dilution in DMSO with concentrations of $10,5,2.5,1.25,0.625,0.313$, and $0.156 \mathrm{mg} /$ $\mathrm{ml}$ in 96 well plates. DPPH reagent was prepared with $0.04 \%$ w/v) concentration by dissolving $2.37 \mathrm{mg}$ of the DPPH powder in $100 \mathrm{ml}$ methanol solution. DPPH solution was shaken and covered with aluminum foil to minimize the penetration of light. Two hundred microliter of methanolic DPPH solution $\left(6 \times 10^{-5} \mathrm{M}\right)$ was added to all wells and the mixture was covered with aluminum foil and incubated for 30 minutes at room temperature. Then, the absorbance was measured at 517 nm using Elisa reader (Multiskan Ascent, Thermo Electron Corporation). Free radical scavenging activity was determined according to the equation:

Free radical scavenging activity was determined according to the equation:

$$
\text { Free radical scavenging activity }(\%)=\frac{A c-A s}{A c} \times 100 \%
$$

where $A_{\mathrm{S}}$ is the absorbance of the sample and $A_{\mathrm{C}}$ is the absorbance of a negative control.

\section{Antibacterial assay}

Antibacterial activity was determined against cultures of $S$. aureus, B. cereus, Micrococcus sp., E. coli, S. typhimurium, and $P$. aeruginosa using disc diffusion test (DDT), modified from Andriani et al. (2017). DDT was used to test the production of antibacterial compounds from the extracts. Before the plates were prepared, the target bacteria were inoculated in NA overnight. The petri dish was filled with NA and left for overnight. Then, the broths were spread on the agar using sterile cotton bud. The methanol crude extracts were diluted with appropriate solvents and were put onto the sterile paper discs (Whatman; $6 \mathrm{~mm}$ diameter) in about $50 \mu \mathrm{l}$ for each disc. The discs were air-dried before placed on the petri dish. Some antibiotics were used as positive control followed by incubation at $37^{\circ} \mathrm{C}$ for 24 hours. The inhibitions zone were examined and measured. The extracts would be considered active when the diameter of the inhibition zones was more than $6 \mathrm{~mm}$.

\section{Thin layer chromatography}

The extracts were diluted in the appropriate amount of solvent and were spotted on thin layer chromatography 
(TLC) Silica gel $60 F_{254}$ plastic plate (Merck 1.05735.0001) which were pre-coated with silica gel $60 F_{254}$. Then, the plate was placed in a developing chamber with a mixture of solvent and the tank was closed. In this study, the best solvent system that could be used for profiling was a mixture of hexane and ethyl acetate (7:3) and dichloromethane with methanol (9:1). Then, the plate was taken out after a while and left to dry. The plate was observed under UV light and the observed spot was marked. The plates were also visualized using Dragendorff's reagent.

\section{Data analysis}

All the experiments in this current study were conducted in triplicate and the data are presented as a mean values \pm standard deviation.

\section{RESULTS AND DISCUSSIONS}

\section{Cytotoxicity screening assay}

The cell viability of all extracts treated is more than $80 \%$ which indicated the extracts were not cytotoxic to the cells. In this study, the inhibition concentrations $\left(\mathrm{IC}_{50}\right)$; the effective dose required to inhibit the proliferative response by $50 \%$ (1), of all extracts were reached more than $30 \mu \mathrm{g} / \mathrm{ml}$. The $\mathrm{IC}_{50}$ values also indicate the proliferative activities of the methanolic extracts of A. planci, E. luzonicus, and E. calamaris towards the HepG2 cells. Cheng et al. (2009) described the isolated compound from an Asteroid; Culcita noveaguinea has the anticancer properties towards human glioblastoma (U87MG) cells. Since the species was in the same class as $A$. planci and E. luzonicus, they were expected to produce similar results if the same type of cells in the previous study were used. In this study, all results (Figs. 1-3) signified that

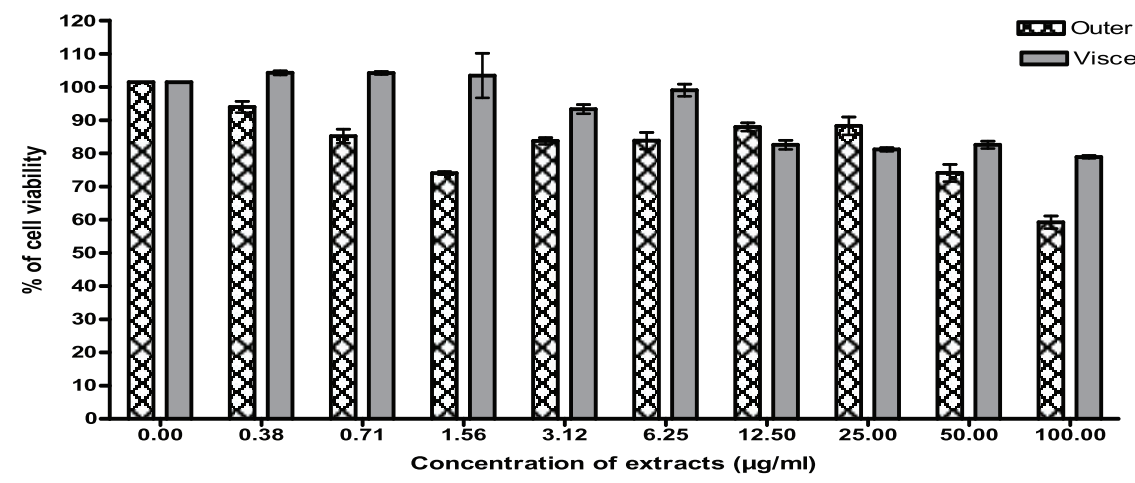

Figure 1. The percentage of HepG2 cell viability against the concentration of methanolic extracts $(\mu \mathrm{g} / \mathrm{ml})$ of $A$. planci, $\mathrm{IC}_{50}>30 \mu \mathrm{g} / \mathrm{ml}$.

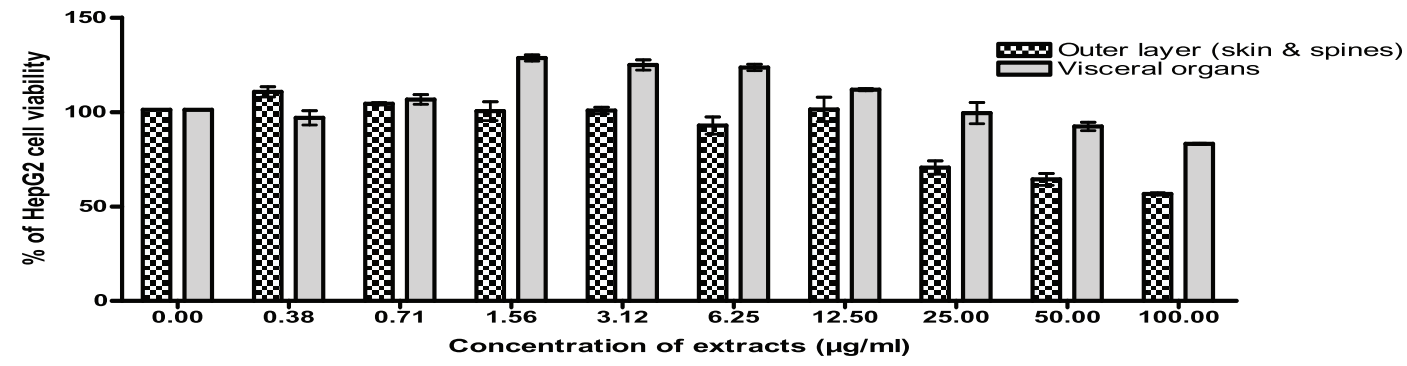

Figure 2. The percentage of $\mathrm{HepG} 2$ cells viability against the concentration of methanolic extracts $(\mu \mathrm{g} / \mathrm{ml})$ of E. calamaris, $\mathrm{IC}_{50}>30 \mu \mathrm{g} / \mathrm{ml}$.

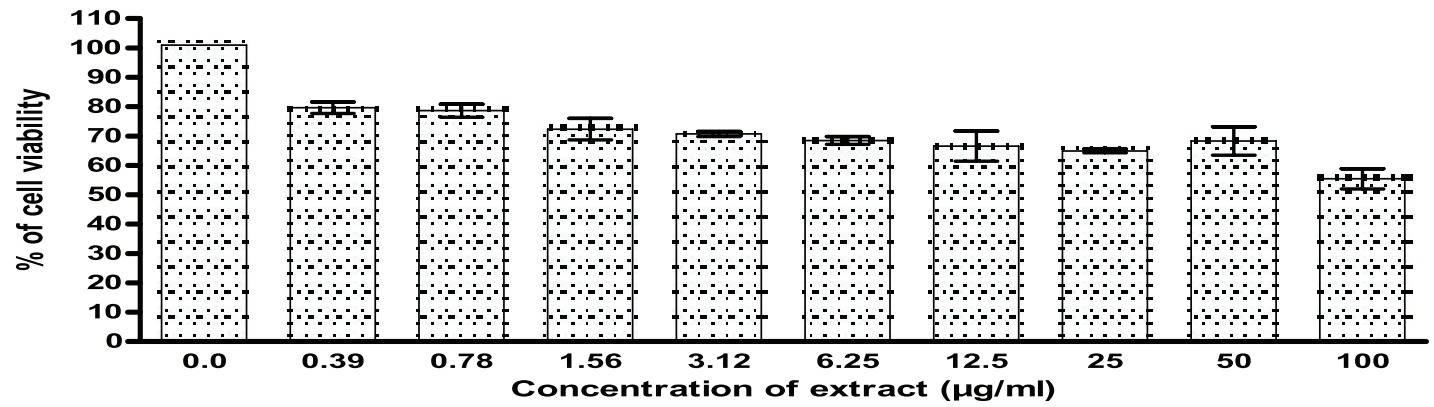

Figure 3. The percentage of HepG2 cell viability against the concentration of methanolic extracts $(\mu \mathrm{g} / \mathrm{ml})$ of E. luzonicus, $\mathrm{IC}_{50}>30 \mu \mathrm{g} / \mathrm{ml}$. 


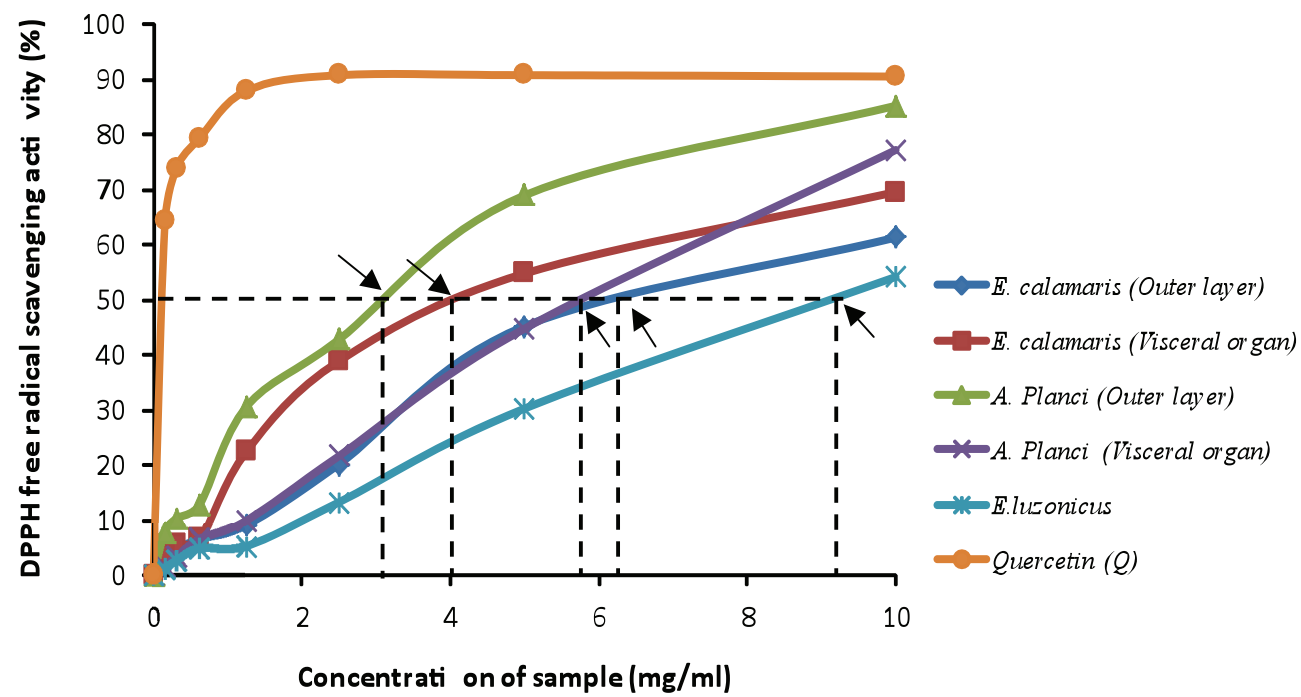

Figure 4. DPPH free radical scavenging activity of A. planci, E. luzonicus, and E. calamaris. The black arrow indicated for $\mathrm{IC}_{50}$ value.

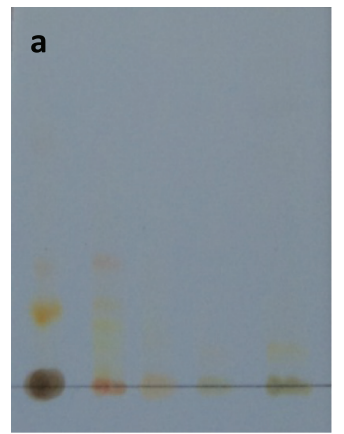

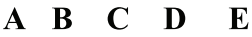

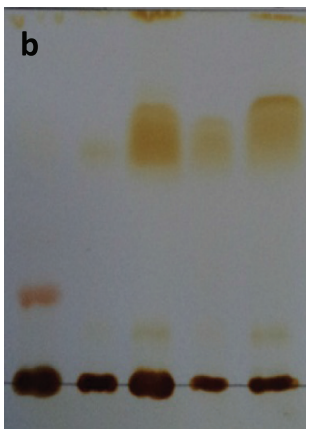

A $\quad$ B $\quad$ C $\quad \mathbf{D} \quad \mathbf{E}$

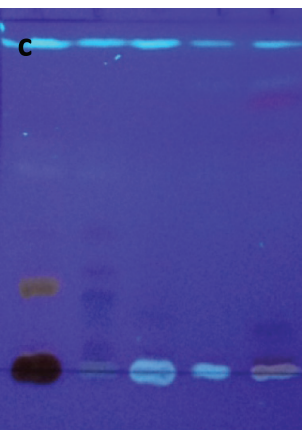

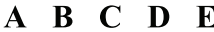

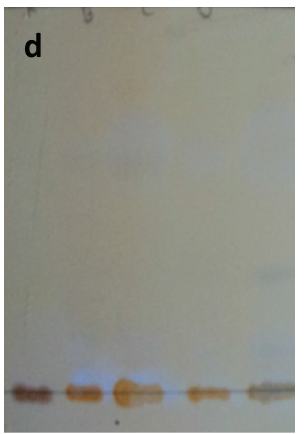

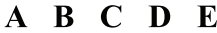

Figure 5. TLC using solvent system of Hexane: Ethyl acetate (7:3) viewed under (a) naked eyes, (b) Iodine vapor, (c) UV longwave (365 nm), and (d) Dragendorff's reagent.

the extracts did not exhibit anticancer properties towards HepG2 cells. There was also a possibility if the extracts undergone the isolation for a pure compound, they would give different results. However, higher inhibition of cell growth was observed at 100 $\mu \mathrm{g} / \mathrm{ml}$ of the extract of the outer layer of A. planci in Figure 1, where the inhibition was almost $50 \%$. This might be due to that outer layer consists of venomous spines of the organisms that hold cytotoxic compounds for body protection. A previous study by Watanabe et al. (2009) has figured that the plancitoxin I, the major lethal factor from the spines of $A$. planci has potent hepatoxicity. They also reported that the toxin exhibits DNase activity responsible for the hepatoxicity. This study has indicated that $A$. planci has a potential in drug discovery studies. As shown in Fig. 2, the outer layer of E. calamaris inhibits the cell growth more than visceral organs. Therefore, the extracts showed anti-proliferative activity with the highest concentration of extracts. However, the inhibitions were still not cytotoxic compared to the positive control, vincristine sulfate which is merely cytotoxic towards the cell with $\mathrm{IC}_{50}$ of $0.09 \mu \mathrm{g} / \mathrm{ml}$. Although at the highest concentration of extracts inhibit the cell, they were still not as cytotoxic activity and also no $\mathrm{IC}_{50}$ value until $100 \mu \mathrm{g} / \mathrm{ml}$. Some studies reported that starfish E. luzonicus rich by steroid glycosides compounds such as Luzonicosides A and B. They were found to have an inhibitory activity against human malignant melanoma cells (RPMI-7951 and SK-Mel-28 cells) (Malyarenko et al., 2017). Furthermore, cytotoxic activity, antibacterial, antitumor, antifungal, antifouling, antiviral, and anticancer preventive effects of steroid glycosides from starfish $E$. luzonicus were also investigated by some researchers (Dong et al., 2011; Ivanchina et al., 2011; 2017; Minale et al., 1993).

\section{Antioxidant activity}

Figure 4 shows samples of A. planci, E. luzonicus, and E. calamari exhibited DPPH free radical scavenging activity. The highest activity was revealed by $A$. planci from the outer layer with the $\mathrm{IC}_{50}$ value of $3.10 \pm 0.13 \mu \mathrm{g} / \mathrm{ml}$, followed by $E$. calamaris and $E$. luzonicus with the $\mathrm{IC}_{50}$ value range from $4.00 \pm 0.65 \mu \mathrm{g} / \mathrm{ml}$ to $9.20 \pm 0.20 \mathrm{mg} / \mathrm{ml}$. The lowest antioxidant activity was obtained by $E$. luzonicus with the $\mathrm{IC}_{50}$ value of $9.20 \pm 0.20 \mathrm{mg} / \mathrm{ml}$. 
Table 1. Antibacterial activity of A. planci, E.luzonicus, and E. calamaris.

\begin{tabular}{|c|c|c|c|c|c|c|}
\hline \multirow{2}{*}{ Name of sample } & \multicolumn{6}{|c|}{ Bacteria strain } \\
\hline & S. aureus & B. cereus & Micrococcus sp. & E. coli & S. typhimurium & P. aeruginosa \\
\hline \multicolumn{7}{|l|}{ A. planci } \\
\hline Outer layer & - & - & $17 \pm 0.23$ & - & - & - \\
\hline Visceral organ & - & - & $16 \pm 0.55$ & - & - & - \\
\hline \multicolumn{7}{|l|}{ E. calamaris } \\
\hline Outer layer & - & - & $18 \pm 0.26$ & - & - & - \\
\hline Visceral organ & - & - & $19 \pm 0.33$ & - & - & - \\
\hline E. luzonicus & - & - & $11 \pm 0.63$ & - & - & - \\
\hline \multicolumn{7}{|l|}{ Antibiotic } \\
\hline Tetracycline & - & $19 \pm 0.25$ & $22 \pm 0.91$ & $19 \pm 0.28$ & $20 \pm 0.21$ & $14 \pm 0.22$ \\
\hline Penicilin & $9.0 \pm 0.28$ & $14 \pm 0.33$ & $21 \pm 0.33$ & $20 \pm 0.26$ & $18 \pm 0.22$ & - \\
\hline Streptomycin & - & $20 \pm 0.35$ & $19 \pm 0.46$ & $14 \pm 0.08$ & $14 \pm 0.66$ & - \\
\hline Gentamycin & $21 \pm 0.23$ & $20 \pm 0.26$ & $22 \pm 0.66$ & $19 \pm 0.25$ & $18 \pm 0.97$ & $23 \pm 0.61$ \\
\hline DMSO & - & - & - & - & - & - \\
\hline
\end{tabular}

*(-) No activity, weak activity ( $<10 \mathrm{~mm}$ halo), good activity $(10-15 \mathrm{~mm}$ halo), and strong activity $(\geq 15 \mathrm{~mm}$ halo).

According to Hseu et al. (2008), the DPPH can accommodate many samples and it is sensitive enough to detect active samples at low concentrations in a short period. Thus, DPPH is well known and commonly used by researchers to detect the antioxidant potency of the sample. Based on the TLC profiling in Figures 5 and 6 which indicate the presence of alkaloids could be correlated to the antioxidant capacity in this study. According to Liu et al. (2014) and Utkina (2009), alkaloids possessed very good antioxidant activity. Beside alkaloids, phenols (Andriani et al., 2017; Farvin and Jacobsen, 2013), terpenes (Ranjith et al., 2007), and steroid glycosides were might also contribute in possess antioxidant activity (Dong et al., 2011; Ivanchina et al., 2011; 2017; Minale et al., 1993). Thus, different visualization using other kinds of reagent spray will be needed to analyze the presence of more chemicals constituents besides alkaloids in the same species which could be correlated to their activities.

\section{Antibacterial assay}

All the extracts gave negative results towards the tested bacteria strains, except Micrococcus sp. Although they did not inhibit the growth of S. aureus, B. cereus, E. coli, S. typhimurium, and $P$. aeruginosa, they showed strong antibacterial activity only against Micrococcus sp. (Table 1). The highest antibacterial activity was revealed by $E$. calamaris $(19 \pm 0.33$ for visceral organ and 18 \pm 0.26 for outer layer) compared to two another samples, $A$. planci and E. luzonicus. A study reported by (Shamsuddin et al., 2010) showed that the methanolic extracts of E. calamaris showed good inhibition towards Gram-positive bacterium, S. aureus. In addition, a previous study (Bryan et al., 1995) reported the antibacterial activity of ethanolic extracts from two asteroids, Goniaster tesselatus and Astrophyton muricatum towards different bacterial tested, namely Deleya marina (a marine bacterium). This indicates the possibility that the extracts from echinoderms are strainsspecific and selective in terms of antibacterial properties. Besides that, different solvent used for extraction produce different results in antibacterial properties. Although the methanolic crude extracts in our study did not show cytotoxic activity towards the HepG2 cells, previous studies have indicated that these echinoderms have other advantages such as anticoagulant factor (Karasudani et al., 1996) and isolated some bioactive compounds, including steroid glycosides, thornasterols, and the carotenoids (Bhakuni and Rawat, 2005;

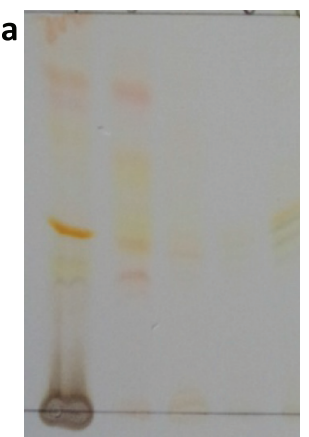

A $\quad$ B $\quad$ C $\quad$ D $\quad$ E

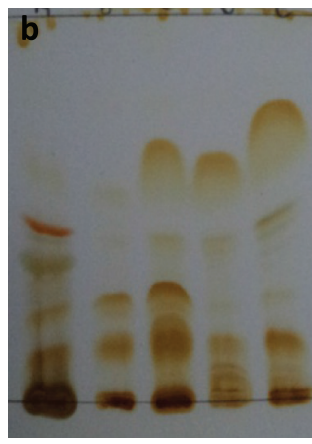

A $\quad$ B $\quad$ C $\quad$ D $\quad$ E

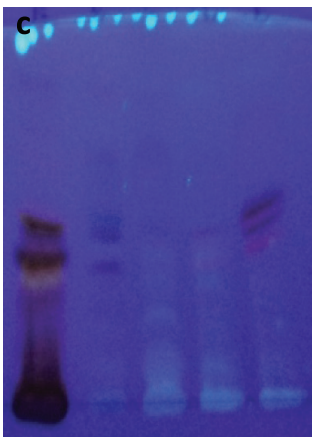

A B C D E

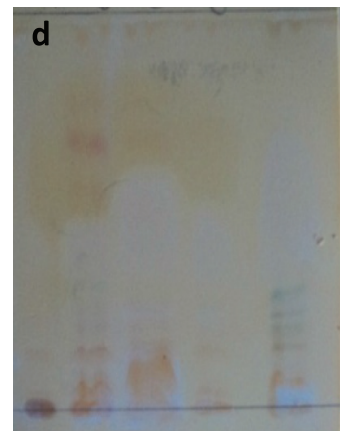

A $\quad$ B $\quad$ C $\quad \mathbf{D} \quad \mathbf{E}$

Figure 6. TLC using solvent system of Dichloromethane: Methanol (9:1) viewed under (a) naked eyes, (b) Iodine vapor, (c) UV longwave (365 nm), and (d) Dragendorff's reagent. *Methanolic extracts of; A: E. luzonicus, B: A. planci (outer layers), C: A. planci (visceral organs), D: E. calamaris (outer layers), and E: E. calamaris (visceral organs). 
Fleming et al., 1974; Kelly, 2005; Maoka et al., 2010). According to Andriani et al. (2017), although the sample used come from the same species, different activity achieved could probably be due to the geographical area of sample collection. In addition, different environmental and habitat of the samples could also effect on their secondary metabolites produced and activities.

\section{Metabolites profiling}

In this study, the sample for metabolites profiling was dissolved and soaked in methanol solvent, a universal and polar solvent where most of the active metabolites such as phenolic, alkaloid, and alkaloid could be extracted. The observation of the metabolites profiling by TLC staining with Dragendorff's reagent showed that alkaloids were present in $A$. planci and $E$. calamaris (Figs. 5 and 6). Some studies reported that alkaloids possess anticancer, antioxidant, and antibacterial activities (Cushnie et al., 2014; Lee et al., 2014; Mute et al., 2012). Besides alkaloids, steroid glycoside, phenols, terpenes, and alkaloid possess antioxidant, antibacterial and cytotoxic activities (Andriani et al., 2017; Dong et al., 2011; Farvin and Jacobsen, 2013; Ivanchina et al., 2011; 2017; Liu et al., 2014; Minale et al., 1993; Ranjith, et al., 2007).

Many compounds from echinoderms, particularly from tissues of the skin are polar or water-soluble components (Cheng et al., 2009). In addition, metabolites from echinoderms are commonly characterized as saponins (Ranjith etal.,2007), and natural alkaloidal saponins were also characterized from another class of Echinoderms, especially Holothuroidea (Bhakuni and Rawat, 2005). To date, saponins are the main metabolites that are responsible for the biological activity of echinoderms. Asterosaponin, a sterol derivatives, which have been isolated are reported to have cytotoxic, antitumor, antibacterial, antifungal and antiviral activities (Cheng et al., 2009; Karasudani et al., 1996; Ma et al., 2009; Ranjith et al., 2007; Tang et al., 2006). Many compounds have been isolated from $A$. planci, such as thymine deoxyriboside, pyrimidine nucleosides, uracil deoxyribose, and others (Bakhuni and Rawat, 2005). While E. luzonicus have reported rich by steroid glycosides compounds which were found to have an anti-inhibitory activity against RPMI-7951 and SK-Mel-28 cells. These compound groups were found to have many bioactivities, such as cytotoxic, antibacterial, antitumor, antifungal, antifouling, antiviral, anticancer activity, etc. (Fleming et al., 1974; Ivanchina et al., 2011; 2017; Minale et al., 1993). Based on the results obtained, echinoderms have the potential as drug candidates to benefit the pharmaceutical area in the future.

\section{CONCLUSION}

The extracts of $A$. planci, E. luzonicus, and E. calamaris showed no cytotoxic activity against HepG2 cells. However, all the extracts of A. planci, E. luzonicus, and E. calamaris revealed very good antioxidant capacity and showed antibacterial potency against Micrococcus sp. that might be useful for biopharmaceuticals industry.

\section{FINANCIAL SUPPORT AND SPONSORSHIP}

The study was supported by a research grant from the Ministry of Science and Technology Malaysia (MOSTI). The author would like to thank University Malaysia Terengganu
Post-Graduate and Horseshoe Crab Laboratories, Biotechnology and Microbiology Laboratories' staff for their hospitality and aid during this project.

\section{CONFLICT OF INTERESTS}

The authors declare no conflict of interest.

\section{REFERENCES}

Andriani Y, Mohamad H, Kassim MNI, Rosnan ND, Syamsumir DF, Saidin J, Tengku Muhammad TS, Amir H. Evaluation on Hydnophytum formicarum Tuber from Setiu Wetland (Malaysia) and Muara Rupit (Indonesia) for antibacterial and antioxidant activities, and anti-cancer Potency against MCF-7 and HeLa Cells. JAPS, 2017; 7(09):030-7.

Andriani Y, Ramli NM, Syamsumir DF, Kassim MNI, Jaafar J, Nur Asniza Azis, Marlina L, Musa NS, Mohamad H. Phytochemical analysis, antioxidant, antibacterial and cytotoxicity Activities of keys and cores part of Pandanus tectorius fruits. Arab J Chem, 2015; doi:10.1016/j. arabjc.2015.11.003

Balboa EM, Conde E, Moure A, Falqué E, Domínguez H. In vitro antioxidant properties of crude extracts and compounds from brown algae. Food Chem, 2013; 138(2-3):1764-85.

Bhakuni DS, Rawat DS. Bioactive marine natural products. Anamaya Publishers, Delhi, India, 2005.

Bryan PJ, Rittschof D, McClintock JB. Bioactivity of echinoderm ethanolic body-wall extracts: an assessment of marine bacterial attachment and macro invertebrate larval settlement. J Exp Mar Biol Ecol, $1995 ; 19: 79-96$.

Cheng G, Zhang X, Tang H-F, Zhang Y, Zhang X-H, Cao W-D, Gao D-K, Wang X-L, Jin B-Q. Asterosaponin 1, a cytostatic compound from the starfish Culcita noveaguinea, functions by inducing apoptosis in human glioblastoma U87MG cells. J Neuro Oncol, 2009; 79(3):235-41.

Cleveland PH Jr, Larry SR, Susan LK, Allan, L. David JE. Animal diversity. 4th edition, Chapter 14, McGraw Hill Publisher, New York, NY, 2007.

Cushnie TPT, Cushnie B, Lamb AJ. Alkaloids: An overview of their antibacterial, antibiotic-enhancing and antivirulence activities. Int $\mathrm{J}$ Antimicrob Agents, 2014; 44(5):377-86.

Dong G, Xu T, Yang B, Lin X, Zhou X, Yang X, Liu Y. Chemical constituents and bioactivities of starfish. Chem Biodivers, 2011; 740-91.

Farvin KHS, Jacobsen C. Phenolic compounds and antioxidant activities of selected species of seaweeds from Danish coast. Food Chem, $2013 ; 138(2-3): 1670-81$.

Fleming WJ, Salathe R, Wyllie SG, Howden MEH. Isolation and partial characterization of steroid glycosides from the starfish Acanthaster planci. Comp Biochem Physiol, 1974; 53b:267-77.

Hseu YC, Chang WH, Chen CS, Liao JW, Huang CJ, Lu FJ, Chia YC, Hsu HK, Wu JJ, Yang HL. Antioxidant activities of Toona sinensis leaves extracts using different antioxidant models. Food Chem Toxicol, $2008 ; 46: 105-14$.

Ivanchina NV, Kicha AA, Malyarenko TV, Stonik VA. Recent studies of polar steroids from starfish: structures, biological activities and biosynthesis. In: Gomes AR, Rocha-Santos T, Duarte A (eds.). Advances in natural products discovery. Nova Science Publishers, Inc, Hauppauge, New York, NY, pp 191-224, 2017.

Ivanchina NV, Kicha AA, Stonik VA. Steroid glycosides from marine organisms. Steroids, 2011; 76:425-54.

Karasudani I, Koyama T, Nakandari S, Aniya Y. Purification of anticoagulant factor from the spine venom of the Crown of Thorns starfish, Acanthaster planci. Toxicon, 1996; 34:871-9.

Kelly MS. Echinoderms: Their culture and bioactive compounds. Prog Mol Subcell Biol, 2005:154-6.

Kitagawa I, Kobayashi M, Sugawara T, Yosioka I. Thornasterol A and B, two genuine sapogenols from the Acanthaster planci. Tetrahedron Lett, 1975; 11:967-70. 
Lee C-C, Hsieh HJ, Hsieh C-H, Hwang DF. Antioxidative and anticancer activities of various ethanolic extract fractions from crown-ofthorns starfish (Acanthaster planci). Environ Toxicol Pharmacol, 2014; 38(3):697-703.

Liu C-M, Kao C-L, Wu HM, Li W-J, Huang C-T, Li H-T, Chen C-Y. Antioxidant and Anticancer Aporphine Alkaloids from the Leaves of Nelumbo nucifera Gaertn. cv. Rosa-plena. Molecules, 2014; (19):17829-38.

Ma XG, Teng HF, Zhao CH, Ma N, Yao MN, Wen AD. Two new 24-hydroxylated asterosaponins from Culcita novaeguinea. Chinese Chem Lett, 2009; 20:1227-30.

Malyarenko OS, Dyshlovoy SA, Kicha AA, Ivanchina NV, Malyarenko TV, Carsten B, Gunhild VA, Stonik VA, Ermakova SP. The inhibitory activity of Luzonicosides from the starfish Echinaster luzonicus against human melanoma cells. Mar Drugs, 2017; 15(7):227.

Maoka T, Akimoto N, Terada Y, Komemushi S, Harada R, Sameshima N, Sakagami Y. Structure of minor carotenoids from the Crownof - thorns starfish, Acanthatser planci. J Nat Pro, 2010; 73(4):675-8.

Minale L, Riccio R, Zollo F. Steroidal oligoglycosides and polyhydroxysteroids from echinoderms. Fortschr Chem Org Naturst, 1993; 62:75-308.

Mutee AF, Salhimi SM, Ghazali FC, Aisha AFA, Lim C-P, Ibrahim K, Asmawi MZ. Evaluation of anti-cancer activity of Acanthester planci extracts obtained by different methods of extraction. Pak J Pharm Sci, 2012; 25(4):697-703.

Shamsuddin AA, Lukman Hakim MD, Kumari GM, Noraznawati I. Anti-bacterial activity of three species of sea urchin extracts from Pulau Bidong, Terengganu. JSSM, 2010; 116-24.
Smith LC, Britten RJ, Davidson EH. Lipopolysaccahride activates the Sea Urchin immune sytem. Dev Comp Immunol, 1995; 19:217-24.

Ranjith NK, Sasikala CH, Ramana CHV. Rhodethrin: a novel indole terpenoid ether produced by Rhodobacter sphaeroides has cytotoxic and phytohormonal activities. Biotechnol Lett, 2007; 29(9):1399-402.

Tang H-F, Yi Y-H, Li L, Sun P, Zhang S-Q, Zhao Y-P. Asterosaponins from the starfish Culcita novaeguinea and their bioactivities. Fitoterapia, 2006; 77:28-34.

Utkina NK. Antioxidant activityofaromatic alkaloids from the marine sponges Aaptos aaptos and Hyrtios sp. Chem Nat Comp, 2009; 45(6):849-53

Watanabe A, Nagashima Y, Shiomi K. Structural characterization of Plancitoxin I, a deoxyribonuclease II-like lethal factor from the crownof-thorns starfish Acanthaster planci, by expression in Chinese hamster ovary cells. Fish Sci, 2009; 75:225-31.

Zakaria Y, Asmah R, Azimahtol HLP, Abdullah NR, Houghton PJ. Eurycomanone induce apoptosis in HepG2 cells via up-regulation of p53. Cancer Cell Int, 2009; 9:16.

How to cite this article:

Andriani Y, Lazim NHM, Asari A, Mohamad F, Muhammad TST, Ismail N, Taib M, Amir H, Ahmad A, Mohamad H. Evaluation of selected echinoderms from peninsular Malaysia for cytotoxicity against HepG2 cells, antioxidant and antibacterial activities, and their metabolites profiling. J App Pharm Sci, 2018; 8(10): 032-038. 